the computation considerably. The method I have outlined can be proved to lead to the same results for $r_{m}$ and $u$ as Thomson's method.

E. A. Peer

The University,

Durham.

April 2.

1 Thomson, G. H., Brit. J. Psychol., 30, 357 (1940),

¿.Hotelling, H., J. Educ. Psychol., 28, 139 (1935).

\section{Densest Packing of Equal Spheres}

THE two equally dense cubic and hexagonal packings discovered by Barlow ${ }^{1}$ in 1883 are now widely known. But it does not appear to be equally well known that there are also four homogeneous mixtures of these ; so that we have in all no less than six homogeneous arrangements all possessing maximum density. Barlow himself was aware of the possibility of admixture ${ }^{2}$, but so far as I know the matter has never been fully expounded, and in view of the increasing practical importance of the subject it is perhaps well that it should be.

When equal plastic spheres are arranged cubically and then uniformly compressed, they become rhombic dodecahedra. Spheres arranged hexagonally become in like circumstances trapezo-rhombic dodecahedra.

Take, therefore, quantities of rhombic dodecahedra $(R)$ and trapezorhombic dodecahedra $(T)$ to represent the Wirkungsbereich of sphere-centres in a homogeneous structure. We note that there cannot be more than two successive layers $(2 R)$ or $(2 T)$ in a homogeneous mixture; for when there are three, the polyhedra in the middle layer are completely sur. rounded, and therefore all polyhedra in additional layers must be surrounded in the same way. In other words, if three successive layers are all $R$ (or $T$ ), then all layers in the structure must be $R$ (or $T$ ), and the arrangement is Barlow's cubic (or hexagonal).

It remains only to determine the possible arrange. ments of polyhedra in which not more than two successive layers are of the same kind, and it is found upon trial that there are four, and no more.

Starting with all layers $R$, substitute a single $T$ layer; we then have:

Homogeneous mixture No. 1. T, $R, R, T, R, R, \ldots$. " $\quad$, No. 2. $\quad R, T, R, T, R, T, \ldots$

Substituting two successive $T$ layers, we have : Homogeneous mixture No. 3. $R, R, T, T, R, R, T, T, \ldots$

where successive letters in a row indicate the nature of successive vertical layers in the structure.

In No. 1 the seventh layer overlies and has the same orientation as the first; in No. 2 the fifth; in No. 3 the thirteenth; and in No. 4 the tenth.

61 Carr Lane, SIDNEY MELMORE

Acomb, York. April 3.

1 Barlow, W., Nature, 29, 186 (1883).

Barlow, W., and Pope, W. J., J. Chem. Soc., 91, 1158 (1907).

\section{Richmondite, a Discredited Mineral Species}

EIGHTY years ago William Skey ${ }^{1,2}$ analysed and described a mineral from Richmond Hill in northwest Nelson, New Zealand, naming it 'richmondite'. His analysis of this material, after deducting 15.4 per cent for siliceous gangue and antimony oxychloride, is as follows: $\mathrm{PbS} 36 \cdot 12, \mathrm{Sb}_{2} \mathrm{~S}_{3} 22 \cdot 20$, $\mathrm{Cu}_{2} \mathrm{~S} 19 \cdot 31, \mathrm{FeS} 13 \cdot 59, \mathrm{ZnS} 5 \cdot 87, \mathrm{Ag}_{2} \mathrm{~S} 2 \cdot 39, \mathrm{MnS}$
$0.52, \mathrm{Bi}_{2} \mathrm{~S}_{3}$ traces: total 100 . From this analysis Skey calculated the formula $\mathrm{Sb}_{2} \mathrm{~S}_{3} .6 R \mathrm{~S}$ (where $R=$ $\mathrm{Pb}, \mathrm{Cu}, \mathrm{Fe}, \mathrm{Ag}, \mathrm{Zn}$ ), and it was his belief that the mineral, though quite distinct from tetrahedrite, was related thereto.

I have prepared polished surfaces from a number of specimens labelled 'Richmondite' that exhibit the properties described by Skey, and I find that not one of these specimens is homogeneous. Instead, the following minerals were found in each specimen : argentian tetrahedrite, galena, sphalerite, chalcopyrite, pyrite, and possibly stromeyerite; these minerals are placed in order of abundance, although in some instances sphalerite is more plentiful than galena. The galena shows no traces of inclusions of argentite, and chemical tests on powder obtained by scratching the surface of the grains did not suggest the presence of any silver in the galena. The tetrahedrite, on the other hand, contains much silver, but unfortunately the powder was not sufficiently pure to warrant a quantitative determination.

Within the tetrahedrite, however, are to be seen occasional, very small inclusions of grey colour that are distinctly anisotropic. The mineral is soft, has a blackish streak, and the standard etch tests give the following reactions: nitric acid, stains iridescent; hydrochloric acid, negative; potassium cyanide, quickly stains black; ferric chloride, stains iridescent; potassium hydroxide, negative; mercuric chloride, stains slowly. These characters are closely comparable to, and suggest, stromeyerite ${ }^{3}$.

Therefore, in view of the lack of homogeneity in the material known as 'richmondite', the latter cannot be considered a true mineral species, and the name should be abandoned.

Department of Geology,

\section{Osborne Hutton}

University of Otago,

Dunedin, New Zealand.

$$
\text { Feb. } 27 .
$$

${ }^{1}$ Skey, W., Trans. N.Z. Inst., 9, 556 (1877).

'Skey, W., 12th Ann. Rept., Col. Mus. and Lab., Wellington (1878).

${ }^{8}$ Short, M. N., U.S. Geol. Sur. Bull. 914 (1940).

\section{Relative Directions of the Electric and Magnetic Vectors in Electromagnetic Waves in vacuo}

IN my recent communication in Nature ${ }^{\mathrm{x}}$ on the relative directions of the electric and magnetic vectors in electromagnetic waves in vacuo, the words "Even if the electric and the magnetic vector were orthogonal to its respective curl (which is not always the case), it would only follow from the Maxwell equations" should be substituted for "It follows from the Maxwell equations". The original version implied that in the electromagnetic waves in vacuo the electric and the magnetic vector is always perpendicular to its respective curl, which is not true, and, apart from this, was superfluous in the main argument.

This correction is the sequel of letters which I have received from Prof. Erwin Schrödinger and from Dr. K. M. Guggenheimer, who wrote to me quite independently about ten days later. To both of them I wish to acknowledge my indebtedness.

Royal Institution, N. S. JAPOLSKY

21 Albemarle Street, London, W.1.

${ }^{1}$ Nature, 159, 580 (1947). 